\title{
OCCURRENCE AND MOLECULAR CHARACTERIZATION OF EXTENDED SPECTRUM BETA-LACTAMASE PRODUCING Enterobacteriaceae IN MILK AND SOME DAIRY PRODUCTS
}

\author{
Walaa Gaffer ${ }^{1}$, Mayada Gwida ${ }^{\star}$, Randa Abo Samra ${ }^{3}$, Maha Al- Ashmawy ${ }^{1}$
}

${ }^{1}$ Department of Food Hygiene and Control, Faculty of Veterinary Medicine, Mansoura Universit, Mansoura 35516, Egypt, ${ }^{2}$ Department of Hygiene and Zoonoses, Faculty of Veterinary Medicine, Mansoura University, Mansoura 35516, Egypt, ${ }^{3}$ Food Inspection Laboratory, Animal Health Research Institute, Damietta Port, Egypt

*Corresponding author, E-mail: mayada_gwida@mans.edu.eg

\begin{abstract}
In the present study a total of one hundred samples were randomly purchased from different supermarkets in Damietta city, Egypt, including 25 samples each of raw milk, ice cream, Kareish and Domiati cheese. The collected samples were screened initially for cefotaxime-resistant bacteria using selective enrichment. The suspected colonies were further characterized by analysis of resistance genes in ESBL-producing isolates. A total of 59 ESBLs producers colonies (24 from raw milk, 15 from kareish cheese, 13 from Domiati cheese and 7 from ice cream) were recovered and identified as Escherichia coli $(n=29)$, Klebsiella pneumonia $(n=8)$, Klebsiella oxytoca $(n=5)$, Enterobacter aerogenes $(n=8)$, Citrobacter diversus $(n=8)$ and Serratia liquefaciens $(n=1)$. Resistance to two or more antibiotics was observed among the recovered isolates. $E$. coli isolates showed high resistance pattern against cefaclor (100\%), cefoxitin (100\%), cefalaxim (96.5\%), ceftazidime (93\%), pencillin (93\%) and 79\% for Pipercillin/Tazobactam. All the recovered Klebseilla spp. isolates were resistant to Cefepime and Pipercillin/Tazobactam ( $84.6 \%$ each) and exhibited $100 \%$ resistant to other antimicrobials agents. Meanwhile, all the recovered isolates were sensitive to imipenem and meropenem. Gene encoding blaCTX-M1 was mostly predominant among screened genes, being present in 13 (48\%) dairy samples for blaTEM and blaSHV, they were detected in $12(44 \%)$ and 4 $(14.8 \%)$ isolates, respectively. In conclusion, there is clear evidence of circulation of antibiotic-resistant food borne ESBL producing Enterobacteriaceae in the examined dairy samples. The concern about increasing the risk of dissemination of such multi-drug resistant pathogens rises with a potential asymptomatic colonization and complication of systemic infection in human subjects. There is also a possible interface for the exchange of resistance genes within and across species and with commensal bacteria of the human and animals.
\end{abstract}

Key words: dairy products; ESBL producing Enterobacteriaceae; Egypt; public health

Introduction
The emergence of antimicrobial resistance foodborne zoonotic bacteria, particularly Enter- 
obacteriaceae that carry ESBLs, has been recognized as one of the most important global problems in both veterinary and human medicine (1). As a matter of growing concern, livestock and animal-derived foods especially milk and its products are the most incriminated foods of animal origin that is linked to disease outbreaks around the word and represent important reservoirs for ESBLs-producing Enterobacteriaceae (2). Escherichia coli and Klebsiella pneumoniae are considered the most predominant species of ESBLs producing Enterobacteriaceae worldwide and are being the causal of urinary tract infections, pneumonia and sepsis in human patients (3). In most of developing countries involving Egypt, there are no restricted rules for the use of antibiotics for the treatments of dairy ailments particularly third and fourth generations of cephalosporin due to their therapeutic effectiveness or their short withdrawal periods. Hence, massive and indiscriminate use of these antibacterial agents is critically important to dairy farming and could have the potential to the spread of ESBLs-producing bacteria or even multi drug resistance (MDR) pathogens (4). Resistance to $\beta$ - lactamase in the family Enterobacteriaceae has been reported to be linked to the production of class $A$ and $C \beta$-lactamase enzymes which able to hydrolyze and inactivate the $\beta$-lactam ring and confer different degrees of resistance to various $\beta$ - lactam classes (5). ESBLs are bacterial enzymes that degrade oxyiminocephalosporins with the most clinically important class A $\beta$-lactamase enzymes and plasmid-mediated Temoniera (TEM), sulfhydryl variable (SHV), and Cefotaxime-Munich $(C T X-M)$ types are the three main families of ESBLs (6).

Raw milk can be contaminated with ESBLs producing Enterobacteriaceae in several entities such as mastitis, directly by animal feces or indirectly during milking (7). Unfortunately, the vast majority of the population in Egypt's, especially in rural families, still consume raw dairy products without pasteurization including traditional Egyptian cheese as Kareish and Domiati cheese (most popular soft white cheese) with a general believe that pasteurization would drastically affect the milk quality
(8). To date, very limited information existing regarding ESBLs producing Enterobacteriaceae isolated from dairy cattle (3). Therefore, it is of utmost significance to address the potential occurrence of ESBLs producing Enterobacteriaceae from raw milk and some dairy products which marketed in different localities in Damietta Governorate, Egypt and to highlight the threats to human health posed by consumption of raw milk and dairy products.

\section{Materials and methods}

\section{Sampling and sample preparation}

A total of 100 samples (25 each of market raw milk, Kareish cheese, Domiati cheese and small scale ice cream) were randomly purchased from groceries, retail outlets, supermarkets in Damietta city, Egypt in March 2018. All the collected samples were transported immediately in coolers in its original package under aseptic conditions to the laboratory for bacteriological examinations which were started quickly after receiving the samples according to the previously described protocol (9).

\section{Isolation and identification of cefotaxime- resistant bacteria}

Twenty five $\mathrm{ml}$ or $\mathrm{g}$ of each dairy samples were diluted with $225 \mathrm{ml}$ of buffered peptone water (BPW). In case of cheese, samples were homogenized in a stomacher for through mixing. All the prepared samples were immediately plated onto MacConkey agar plates (Oxoid, Basingstoke, UK) supplemented with $1 \mathrm{mg} / \mathrm{L}$ cefotaxime (Sigma-Aldrich) and incubated for $24 \mathrm{~h}$ at $37{ }^{\circ} \mathrm{C}$. At least three grown colonies were selected and sub-cultured onto MacConkey agar supplemented with $1 \mathrm{mg} / \mathrm{L}$ cefotaxime at $37{ }^{\circ} \mathrm{C}$ for $24 \mathrm{~h}$ to obtain pure cultures for subsequent analysis. Bacterial characterization was performed using Gram staining, and conventional biochemical testing including Oxidase, indole, methyl red, vogus-prauskaur, citrate, and urease.

\section{Serotyping of identified E. coli}

Serotyping of biochemically confirmed $E$. coli isolates were performed by agglutination tests by using rapid diagnostic $E$.coli antisera 
sets according to the previously described protocol (10) (Denka Seiken Co., Japan) at Food Analysis Center, Faculty of Veterinary Medicine, Benha University, Egypt.

Antimicrobial susceptibility testing and ESBLs detection

All recovered isolates were screened for susceptibility test using 13 antimicrobial agents on Mueller-Hinton agar using disc diffusion method and evaluated according to CLSI criteria (11). The following antimicrobial discs were applied: Penicillin G. (P $10 \mu \mathrm{g}$ ), Ampicillin (AM10 $\mu \mathrm{g}$ ), Imipenem (IPM $10 \mu \mathrm{g}$ ), Meropenem (MEM $10 \mu \mathrm{g}$ ), Cefalaxin (CL $30 \mu \mathrm{g}$ ), Cefaclor (CEC30 $\mu \mathrm{g}$ ), Cefoxitin (FOX $30 \mu \mathrm{g}$ ), Ceftazidime (CAZ $30 \mu \mathrm{g}$ ), Cefotaxime (CTX $30 \mu \mathrm{g}$ ), Cefepime (FEP $30 \mu \mathrm{g}$ ), Azteonam (ATM $30 \mu \mathrm{g}$ ), Amoxicillin-clavulinic (AMC 20/10 $\mu \mathrm{g}$ ), Piperacillin-tazobactam (Tpz 100/10). Each isolate that exhibited resistant to one or more of the third and fourth-generation cephalosporins were confirmed for ESBL production by Double Disk Synergy Test (DDST) according to CLSI guidelines.

\section{Characterization of $\beta$-lactamases}

Genomic bacterial DNA was extracted from the identified ESBLs producers E. coli $(\mathrm{n}=17)$ and Klebseilla $\operatorname{spp}(\mathrm{n}=10)$ using the QIAamp ${ }^{\circledR}$ DNA Mini Kit Qiagen according to the manufacturer's guidelines. The purified DNA was further analyzed by PCR targeting ESBL encoding genes including blaTEM, blaSHV and blaCTX-M using specific oligonucleotide primers sequences and PCR conditions as described previously (Table 1).

\section{Results}

Out of hundred dairy samples, 30 yielded bacterial growth on MacConkey agar supple mented with cefotaxime : $8(32 \%)$ from raw milk, 8 (32\%) from Domiati cheese, 9 (36\%) from kareish cheese and $5(20 \%)$ from ice cream. Overall, 59 ESBLs producers colonies (24 came from raw milk, 15 from kareish cheese, 13 from Damietta cheese and 7 from ice cream) and were biochemically identified as $E$. coli $(\mathrm{n}=29,49 \%)$, Klebsiella pneumonia $(\mathrm{n}=$ $8,13.5 \%)$, Klebsiella oxytoca $(\mathrm{n}=5,8.5 \%)$, Enterobacter aerogenes $(\mathrm{n}=8,13.5 \%)$, Citrobacter diversus $(\mathrm{n}=8,13.5 \%)$ and Serratia liquefaciens $(\mathrm{n}=1,1.7 \%)$ (Table $2 \& 3)$. The most prevalent phenotype was E.coli $(\mathrm{n}=17,17 \%)$, Klebsiella pneumonia $(\mathrm{n}=6,6 \%), 5(5 \%)$ for each of Enterobacter aerogenes and Citrobacter diversus, 4 (4\%) for Klebsiella oxytoca and 1 (1\%) for Serratia liquefaciens (Table 3).

The pattern of antimicrobial drug susceptibility for the 59 ESBLs producers are presented in Table 4\&5. Briefly, E. coli isolates showed high resistance pattern against cefaclor $(100 \%)$, cefoxitin (100\%), cefalaxim (96.5\%), ceftazidime $(93 \%)$, pencillin $(93 \%)$ and $79 \%$ for Pipercillin/Tazobactam. All the recovered Klebseilla spp. isolates $(\mathrm{n}=13)$ were resistant to Pencillin, Ampicillin, Cefalaxim, cefaclor, Cefoxitin and Ceftazidime (100\% each) and to Cefepime and Pipercillin/Tazobactam (84.6\% each). On the other side, all recovered isolates were sensitive to imipenem and meropenem. Gene encoding blaCTX-M1 was mostly predominant among screened genes (fig 1\&2), being present in $13(48 \%)$ dairy samples. for blaTEM and blaSHV, they were detected in 12 $(44 \%)$ and $4(14.8 \%)$ isolates, respectively. Three isolates harbored the three screened $\beta$ lactamase genes; blaCTX-M1 and blaTEM were detected in four isolates; while blaSHV and blaCTX-M1 were observed in one isolate.

Table 1: Oligonucleotide primers sequences used for amplification of B-lactamase resistance genes

\begin{tabular}{|c|c|c|c|}
\hline Target gene & Oligonucleotide sequence $\left(5^{\prime} \rightarrow 3^{\prime}\right)$ & Product size (bp) & References \\
\hline blaCTX-MI (F) & 5' TTAGGAAGTGTGCCGCTGTA '3 & 655 & 12 \\
\hline blaCTX-M1 (R) & 5' CGGTTTTATCCCCCACAAC'3 & & \\
\hline $\operatorname{blaSHV}(\mathrm{F})$ & 5' AGCCGCTTGAGCAAATTAAAC '3 & & 13 \\
\hline blaSHV (R) & 5' ATCCCGCAGATAAATCACCAC '3 & 713 & \\
\hline blaTEM $(\mathrm{F})$ & 5' CATTTCCGTGTCGCCCTTATTC '3 & & 13 \\
\hline $\operatorname{blaTEM}(R)$ & 5' CGTTCATCCATAGTTGCCTGAC '3 & 800 & \\
\hline
\end{tabular}


Table 2: Distribution of ESBLs producers Enterobacteriacea spp. from the examined dairy samples

\begin{tabular}{|c|c|c|c|c|c|c|c|}
\hline \multirow{2}{*}{$\begin{array}{l}\text { Sample } \\
\text { number }\end{array}$} & \multirow[t]{2}{*}{ Origin } & \multicolumn{6}{|c|}{ Number of isolated Enterobacteriacea spp. from the positive samples } \\
\hline & & E.coli & K. penumonia & K. oxytoca & $\begin{array}{l}\text { Enterobac- } \\
\text { ter }\end{array}$ & Citrobacter & Serratia \\
\hline & Milk & & & & & & \\
\hline 1 & $\begin{array}{l}\text { Pos } \mathrm{n}=8 / 25 \\
(32 \%)\end{array}$ & 2 & & & & & \\
\hline 6 & & 3 & & & 1 & & \\
\hline 10 & & 3 & & 1 & & & \\
\hline 11 & & & & & & 3 & \\
\hline 12 & & & & & 2 & 1 & 1 \\
\hline 13 & & 1 & & 1 & & & \\
\hline 14 & & & & & 3 & & \\
\hline \multirow[t]{2}{*}{21} & & & 2 & & & & \\
\hline & $\begin{array}{l}\text { Damietta } \\
\text { chesses }\end{array}$ & & & & & & \\
\hline 23 & $\begin{array}{l}\text { Pos } \mathrm{n}=8 / 25 \\
(32 \%)\end{array}$ & & & 1 & & & \\
\hline 27 & & 1 & 1 & & & & \\
\hline 29 & & 2 & & & & & \\
\hline 31 & & & 1 & & & & \\
\hline 35 & & & & & 1 & & \\
\hline 41 & & 1 & 1 & & & & \\
\hline 43 & & 1 & & & & & \\
\hline \multirow[t]{2}{*}{49} & & & & & & 1 & \\
\hline & Kariesh cheese & & & & & & \\
\hline 51 & $\begin{array}{l}\text { Pos } n=9 / 25 \\
(36 \%)\end{array}$ & & & 2 & & & \\
\hline 54 & & 1 & & & & & \\
\hline 58 & & & & & & 2 & \\
\hline 59 & & 1 & & & & 1 & \\
\hline 61 & & 2 & & & & & \\
\hline 69 & & 1 & & & & & \\
\hline 70 & & 3 & & & & & \\
\hline 74 & & 2 & & & & & \\
\hline \multirow[t]{2}{*}{75} & & & 2 & & & & \\
\hline & Ice Cream & & & & & & \\
\hline 79 & $\begin{array}{l}\text { Pos } \mathrm{n}=5 / 25 \\
(20 \%)\end{array}$ & & 1 & & & & \\
\hline 80 & & 2 & & & & & \\
\hline 83 & & 2 & & & & & \\
\hline 94 & & 1 & & & & & \\
\hline \multirow[t]{2}{*}{97} & & & & & 1 & & \\
\hline & $\begin{array}{l}\text { Total pos } \mathrm{n}= \\
30 / 100(30 \%)\end{array}$ & 29 & 8 & 5 & 8 & 8 & 1 \\
\hline
\end{tabular}


Table 3: Occurrence and distribution of different ESBLs producers Enterobacteriaceae spp. in examined dairy samples

\begin{tabular}{|c|c|c|c|c|c|c|c|c|c|c|}
\hline \multirow{2}{*}{$\begin{array}{l}\text { Enterobacte- } \\
\text { riacae spp. }\end{array}$} & \multicolumn{2}{|c|}{ Milk $n=25$} & \multicolumn{2}{|c|}{$\begin{array}{l}\text { Kariesh cheese } n \\
=25\end{array}$} & \multicolumn{2}{|c|}{$\begin{array}{l}\text { Damietta cheese } n \\
=25\end{array}$} & \multicolumn{2}{|c|}{ Ice Cream $n=25$} & \multicolumn{2}{|c|}{$\begin{array}{l}\text { Total } \\
\text { Dairy samples }\end{array}$} \\
\hline & $\begin{array}{l}\text { Pos } \\
\text { sam- } \\
\text { ples }\end{array}$ & $\begin{array}{l}\mathrm{N} \text { of } \\
\text { colo- } \\
\text { nies }\end{array}$ & $\begin{array}{l}\text { Pos } \\
\text { sam- } \\
\text { ples }\end{array}$ & $\begin{array}{l}\mathrm{N} \text { of } \\
\text { colo- } \\
\text { nies }\end{array}$ & $\begin{array}{l}\text { Pos } \\
\text { samples }\end{array}$ & $\begin{array}{l}\mathrm{N} \text { of } \\
\text { colo- } \\
\text { nies }\end{array}$ & $\begin{array}{l}\text { Pos } \\
\text { samples }\end{array}$ & $\begin{array}{l}\mathrm{N} \text { of } \\
\text { colo- } \\
\text { nies }\end{array}$ & $\begin{array}{l}\text { Pos } \\
\text { samples }\end{array}$ & $\begin{array}{l}\mathrm{N} \text { of } \\
\text { colonies }\end{array}$ \\
\hline E.coli & $\begin{array}{l}4 \\
(16 \%)\end{array}$ & 9 & $\begin{array}{l}6 \\
(24 \%)\end{array}$ & 10 & $4(16 \%)$ & 5 & $3(12 \%)$ & 5 & $\begin{array}{l}17 \\
(17 \%)\end{array}$ & 29 \\
\hline $\begin{array}{l}\text { Klebseilla } \\
\text {.pneumoniae }\end{array}$ & $1(4 \%)$ & 2 & $1(4 \%)$ & 2 & $3(12 \%)$ & 3 & $1(4 \%)$ & 1 & $6(6 \%)$ & 8 \\
\hline $\begin{array}{l}\text { Klebseilla.oxy- } \\
\text { toca }\end{array}$ & $2(8 \%)$ & 2 & $1(4 \%)$ & 2 & $1(4 \%)$ & 1 & 0 & 0 & $4(4 \%)$ & 5 \\
\hline $\begin{array}{l}\text { Enterobacter } \\
\text { aerogenes }\end{array}$ & $\begin{array}{l}3 \\
(12 \%)\end{array}$ & 6 & 0 & 0 & $1(4 \%)$ & 1 & $1(4 \%)$ & 1 & $5(5 \%)$ & 8 \\
\hline $\begin{array}{l}\text { Citrobacter di- } \\
\text { versus }\end{array}$ & $2(8 \%)$ & 4 & $2(8 \%)$ & 3 & $1(4 \%)$ & 1 & 0 & 0 & $5(5 \%)$ & 8 \\
\hline $\begin{array}{l}\text { Serratia lique- } \\
\text { faciens }\end{array}$ & $1(4 \%)$ & 1 & 0 & 0 & 0 & 0 & - & 0 & $1(1 \%)$ & 1 \\
\hline $\begin{array}{l}\text { Total number } \\
\text { of ESBLs } n=59\end{array}$ & & 24 & & 17 & & 11 & & 7 & & 59 \\
\hline
\end{tabular}


Table 4: Characteristics of ESBL-positive Enterobacteriaceae identified from dairy samples

\begin{tabular}{|c|c|c|c|c|c|c|c|c|c|c|c|c|c|c|c|}
\hline \multirow{2}{*}{$\begin{array}{l}\text { Sam- } \\
\text { ple } \\
\text { num- } \\
\text { ber }\end{array}$} & \multirow[t]{2}{*}{ Origin } & \multirow[t]{2}{*}{ Species } & \multicolumn{13}{|c|}{ b-lactam antibiotic resistances } \\
\hline & & & $\mathrm{P}$ & AM & IPM & MEM & $\mathrm{CL}$ & CEC & FOX & CAZ & CTX & FEP & ATM & AMC & TPZ \\
\hline 1 & Milk & E.col (O128:H2) & $\mathrm{R}$ & $\mathrm{R}$ & $\mathrm{S}$ & $\mathrm{S}$ & $\mathrm{R}$ & $\mathrm{R}$ & $\mathrm{R}$ & $\mathrm{R}$ & $\mathrm{R}$ & $\mathrm{S}$ & $\mathrm{R}$ & $\mathrm{R}$ & $\mathrm{R}$ \\
\hline 1 & Milk & E.coli $(\mathrm{O} 91: \mathrm{H} 21)$ & $\mathrm{R}$ & $\mathrm{R}$ & $\mathrm{S}$ & $\mathrm{S}$ & $\mathrm{R}$ & $\mathrm{R}$ & $\mathrm{R}$ & $\mathrm{R}$ & $\mathrm{R}$ & $\mathrm{S}$ & $\mathrm{S}$ & $\mathrm{R}$ & $\mathrm{R}$ \\
\hline 6 & Milk & E.coli (O55:H7) & $\mathrm{R}$ & $\mathrm{S}$ & $\mathrm{S}$ & $\mathrm{S}$ & $\mathrm{R}$ & $\mathrm{R}$ & $\mathrm{R}$ & $\mathrm{S}$ & $\mathrm{R}$ & $\mathrm{S}$ & $\mathrm{S}$ & $\mathrm{R}$ & $\mathrm{R}$ \\
\hline 6 & Milk & E.coli (O121:H7) & $\mathrm{R}$ & $\mathrm{R}$ & $\mathrm{S}$ & $\mathrm{S}$ & $\mathrm{R}$ & $\mathrm{R}$ & $\mathrm{R}$ & $\mathrm{R}$ & $\mathrm{R}$ & $\mathrm{R}$ & $\mathrm{S}$ & $\mathrm{S}$ & $\mathrm{R}$ \\
\hline 6 & Milk & $\begin{array}{l}\text { E.coli } \\
\text { (O146:H21) }\end{array}$ & $\mathrm{R}$ & $S$ & $\mathrm{~S}$ & $S$ & $\mathrm{R}$ & $\mathrm{R}$ & $\mathrm{R}$ & $\mathrm{R}$ & $\mathrm{R}$ & $\mathrm{R}$ & S & S & $\mathrm{R}$ \\
\hline 10 & Milk & E.coli (O111:H2) & $\mathrm{R}$ & $\mathrm{R}$ & $\mathrm{S}$ & $\mathrm{S}$ & $\mathrm{R}$ & $\mathrm{R}$ & $\mathrm{R}$ & $\mathrm{R}$ & $\mathrm{R}$ & $\mathrm{R}$ & $\mathrm{S}$ & $\mathrm{S}$ & $\mathrm{S}$ \\
\hline 10 & Milk & E.coli (O111:H2) & $\mathrm{R}$ & $\mathrm{S}$ & $\mathrm{S}$ & $\mathrm{S}$ & $\mathrm{R}$ & $\mathrm{R}$ & $\mathrm{R}$ & $\mathrm{R}$ & $\mathrm{R}$ & $\mathrm{S}$ & $\mathrm{S}$ & $\mathrm{S}$ & $\mathrm{R}$ \\
\hline 10 & Milk & E.coli (O114:H4) & $\mathrm{S}$ & $\mathrm{S}$ & $\mathrm{S}$ & $\mathrm{S}$ & $\mathrm{R}$ & $\mathrm{R}$ & $\mathrm{R}$ & $\mathrm{R}$ & $\mathrm{R}$ & $\mathrm{S}$ & $\mathrm{S}$ & $\mathrm{S}$ & $\mathrm{S}$ \\
\hline 13 & Milk & E.coli ( O78) & $\mathrm{R}$ & $\mathrm{S}$ & $\mathrm{S}$ & $\mathrm{S}$ & $\mathrm{R}$ & $\mathrm{R}$ & $\mathrm{R}$ & $\mathrm{R}$ & $\mathrm{R}$ & $\mathrm{S}$ & $\mathrm{S}$ & $\mathrm{S}$ & $\mathrm{S}$ \\
\hline 27 & $\begin{array}{l}\text { Domiate } \\
\text { cheese }\end{array}$ & E.coli (O111:H2) & $\mathrm{R}$ & $\mathrm{R}$ & $\mathrm{S}$ & $\mathrm{S}$ & $\mathrm{R}$ & $\mathrm{R}$ & $\mathrm{R}$ & $\mathrm{R}$ & $\mathrm{R}$ & $\mathrm{R}$ & $\mathrm{R}$ & $\mathrm{R}$ & $\mathrm{R}$ \\
\hline 29 & $\begin{array}{l}\text { Domiate } \\
\text { cheese }\end{array}$ & E.coli $(\mathrm{O} 121: \mathrm{H} 7)$ & $\mathrm{R}$ & $\mathrm{R}$ & S & $S$ & $\mathrm{R}$ & $\mathrm{R}$ & $\mathrm{R}$ & $\mathrm{R}$ & $\mathrm{R}$ & $\mathrm{R}$ & $\mathrm{R}$ & $\mathrm{R}$ & $\mathrm{R}$ \\
\hline 29 & $\begin{array}{l}\text { Domiate } \\
\text { cheese }\end{array}$ & E.coli ( O26:H11) & $\mathrm{R}$ & $\mathrm{S}$ & $\mathrm{S}$ & $S$ & $\mathrm{R}$ & $\mathrm{R}$ & $\mathrm{R}$ & $\mathrm{R}$ & $\mathrm{R}$ & $\mathrm{R}$ & S & $S$ & $\mathrm{R}$ \\
\hline 41 & $\begin{array}{l}\text { Domiate } \\
\text { cheese }\end{array}$ & E.coli (O26:H11) & $\mathrm{R}$ & $S$ & $S$ & $\mathrm{~S}$ & $\mathrm{R}$ & $\mathrm{R}$ & $\mathrm{R}$ & $\mathrm{R}$ & $\mathrm{R}$ & $\mathrm{S}$ & S & $\mathrm{S}$ & $\mathrm{R}$ \\
\hline 43 & $\begin{array}{l}\text { Domiate } \\
\text { cheese }\end{array}$ & E.coli (O114:H4) & $\mathrm{R}$ & $\mathrm{R}$ & $S$ & $S$ & $\mathrm{R}$ & $\mathrm{R}$ & $\mathrm{R}$ & $\mathrm{R}$ & $\mathrm{R}$ & $\mathrm{R}$ & S & $\mathrm{R}$ & $\mathrm{R}$ \\
\hline 54 & $\begin{array}{l}\text { kareish } \\
\text { cheese }\end{array}$ & E.coli (O124) & $\mathrm{R}$ & $\mathrm{R}$ & $\mathrm{S}$ & S & $\mathrm{R}$ & $\mathrm{R}$ & $\mathrm{R}$ & $\mathrm{R}$ & $\mathrm{R}$ & $\mathrm{R}$ & S & $\mathrm{R}$ & $\mathrm{R}$ \\
\hline 59 & $\begin{array}{l}\text { kareish } \\
\text { cheese }\end{array}$ & E.coli (O111:H2) & $\mathrm{R}$ & $\mathrm{R}$ & $\mathrm{S}$ & $\mathrm{S}$ & $\mathrm{R}$ & $\mathrm{R}$ & $\mathrm{R}$ & $\mathrm{R}$ & $\mathrm{R}$ & $\mathrm{R}$ & $\mathrm{S}$ & $\mathrm{R}$ & $\mathrm{R}$ \\
\hline 61 & $\begin{array}{l}\text { kareish } \\
\text { cheese }\end{array}$ & E.coli (O91:H21) & $\mathrm{R}$ & $S$ & S & $S$ & $\mathrm{R}$ & $\mathrm{R}$ & $\mathrm{R}$ & $\mathrm{R}$ & $\mathrm{R}$ & S & S & $S$ & $\mathrm{R}$ \\
\hline 61 & $\begin{array}{l}\text { kareish } \\
\text { cheese }\end{array}$ & E.coli (O121:H7) & $\mathrm{R}$ & $\mathrm{S}$ & $\mathrm{S}$ & $\mathrm{S}$ & $\mathrm{S}$ & $\mathrm{R}$ & $\mathrm{R}$ & $\mathrm{R}$ & $\mathrm{R}$ & S & S & S & S \\
\hline 69 & $\begin{array}{l}\text { kareish } \\
\text { cheese }\end{array}$ & E.coli (O91:H21) & $\mathrm{R}$ & $\mathrm{S}$ & $\mathrm{S}$ & $\mathrm{S}$ & $\mathrm{R}$ & $\mathrm{R}$ & $\mathrm{R}$ & $\mathrm{R}$ & $\mathrm{R}$ & $\mathrm{S}$ & S & $\mathrm{S}$ & $\mathrm{R}$ \\
\hline 70 & $\begin{array}{l}\text { kareish } \\
\text { cheese }\end{array}$ & $\begin{array}{l}\text { E.coli } \\
\text { (O126:H21) }\end{array}$ & $\mathrm{R}$ & $S$ & $S$ & $S$ & $\mathrm{R}$ & $\mathrm{R}$ & $\mathrm{R}$ & $\mathrm{R}$ & $\mathrm{R}$ & $\mathrm{R}$ & S & S & $\mathrm{R}$ \\
\hline 70 & $\begin{array}{l}\text { kareish } \\
\text { cheese }\end{array}$ & E.coli (O128:H2) & $\mathrm{R}$ & $\mathrm{R}$ & $\mathrm{S}$ & $\mathrm{S}$ & $\mathrm{R}$ & $\mathrm{R}$ & $\mathrm{R}$ & $\mathrm{R}$ & $\mathrm{R}$ & S & $\mathrm{R}$ & $\mathrm{R}$ & $\mathrm{R}$ \\
\hline 70 & $\begin{array}{l}\text { kareish } \\
\text { cheese }\end{array}$ & E.col i (O111:H2) & $\mathrm{R}$ & $\mathrm{R}$ & $S$ & $S$ & $\mathrm{R}$ & $\mathrm{R}$ & $\mathrm{R}$ & $\mathrm{R}$ & $\mathrm{R}$ & $S$ & $\mathrm{R}$ & $\mathrm{R}$ & $\mathrm{R}$ \\
\hline 74 & $\begin{array}{l}\text { kareish } \\
\text { cheese }\end{array}$ & E.coli (O127:H6) & $\mathrm{R}$ & $\mathrm{R}$ & S & $S$ & $\mathrm{R}$ & $\mathrm{R}$ & $\mathrm{R}$ & $\mathrm{R}$ & $\mathrm{R}$ & $\mathrm{S}$ & $\mathrm{R}$ & $S$ & $\mathrm{R}$ \\
\hline 74 & $\begin{array}{l}\text { kareish } \\
\text { cheese }\end{array}$ & E.coli(O146:H21) & $R$ & $\mathrm{R}$ & $\mathrm{S}$ & $\mathrm{S}$ & $R$ & $\mathrm{R}$ & $\mathrm{R}$ & $\mathrm{R}$ & $\mathrm{R}$ & $\mathrm{R}$ & $\mathrm{S}$ & $\mathrm{S}$ & $S$ \\
\hline 80 & $\begin{array}{l}\text { Ice } \\
\text { cream }\end{array}$ & E.coli $(\mathrm{O} 26 \mathrm{H} 11)$ & $\mathrm{R}$ & $\mathrm{R}$ & $S$ & $\mathrm{~S}$ & $\mathrm{R}$ & $\mathrm{R}$ & $\mathrm{R}$ & $\mathrm{R}$ & $\mathrm{R}$ & $\mathrm{R}$ & S & $\mathrm{S}$ & S \\
\hline 80 & $\begin{array}{l}\begin{array}{l}\text { Ice } \\
\text { cream }\end{array} \\
\end{array}$ & E.coli (O91:H21) & $\mathrm{R}$ & $\mathrm{R}$ & S & $S$ & $\mathrm{R}$ & $\mathrm{R}$ & $\mathrm{R}$ & $\mathrm{R}$ & $\mathrm{R}$ & $\mathrm{R}$ & S & S & $\mathrm{R}$ \\
\hline 83 & $\begin{array}{l}\begin{array}{l}\text { Ice } \\
\text { cream }\end{array} \\
\end{array}$ & E.coli (O111:H2) & $\mathrm{R}$ & $\mathrm{R}$ & $S$ & S & $\mathrm{R}$ & $\mathrm{R}$ & $\mathrm{R}$ & $\mathrm{R}$ & $\mathrm{R}$ & $\mathrm{R}$ & S & $\mathrm{R}$ & $\mathrm{R}$ \\
\hline 83 & $\begin{array}{l}\begin{array}{l}\text { Ice } \\
\text { cream }\end{array} \\
\end{array}$ & E.coli $(\mathrm{O} 121: \mathrm{H} 7$ & $\mathrm{R}$ & $\mathrm{R}$ & $S$ & $\mathrm{~S}$ & $\mathrm{R}$ & $\mathrm{R}$ & $\mathrm{R}$ & $\mathrm{R}$ & $\mathrm{R}$ & $\mathrm{R}$ & $\mathrm{R}$ & S & $\mathrm{R}$ \\
\hline 94 & $\begin{array}{l}\text { Ice } \\
\text { cream }\end{array}$ & E.coli ( O26:H11) & $\mathrm{R}$ & $\mathrm{S}$ & $\mathrm{S}$ & $S$ & $\mathrm{R}$ & $\mathrm{R}$ & $\mathrm{R}$ & $\mathrm{R}$ & $\mathrm{R}$ & $\mathrm{R}$ & S & $\mathrm{S}$ & $\mathrm{S}$ \\
\hline
\end{tabular}


Table 4: Continuation

\begin{tabular}{|c|c|c|c|c|c|c|c|c|c|c|c|c|c|c|c|}
\hline \multirow{2}{*}{$\begin{array}{l}\text { Sam- } \\
\text { ple } \\
\text { num- } \\
\text { ber }\end{array}$} & \multirow[t]{2}{*}{ Origin } & \multirow[t]{2}{*}{ Species } & \multicolumn{13}{|c|}{ b-lactam antibiotic resistances } \\
\hline & & & $\mathrm{P}$ & $\mathrm{AM}$ & IPM & MEM & CL & CEC & FOX & CAZ & CTX & FEP & ATM & AMC & TPZ \\
\hline 21 & Milk & k. pneom & $\mathrm{R}$ & $\mathrm{R}$ & $\mathrm{S}$ & $\mathrm{S}$ & $\mathrm{R}$ & $\mathrm{R}$ & $\mathrm{R}$ & $\mathrm{R}$ & $\mathrm{R}$ & $\mathrm{R}$ & $\mathrm{R}$ & $\mathrm{S}$ & $S$ \\
\hline 21 & Milk & k. pneom & $\mathrm{R}$ & S & S & $\mathrm{S}$ & $\mathrm{R}$ & $\mathrm{R}$ & $\mathrm{R}$ & $\mathrm{R}$ & $\mathrm{R}$ & $S$ & S & $\mathrm{R}$ & $\mathrm{R}$ \\
\hline 27 & $\begin{array}{l}\text { Domiate } \\
\text { cheese }\end{array}$ & K.pnemo & $\mathrm{R}$ & $\mathrm{R}$ & S & $S$ & $\mathrm{R}$ & $\mathrm{R}$ & $\mathrm{R}$ & $\mathrm{R}$ & $\mathrm{R}$ & $\mathrm{R}$ & $S$ & $\mathrm{~S}$ & $\mathrm{R}$ \\
\hline 31 & $\begin{array}{l}\text { Domiate } \\
\text { cheese }\end{array}$ & K.pnemo & $\mathrm{R}$ & $\mathrm{R}$ & $\mathrm{S}$ & $\mathrm{S}$ & $\mathrm{R}$ & $\mathrm{R}$ & $\mathrm{R}$ & $\mathrm{R}$ & $\mathrm{R}$ & $S$ & S & $\mathrm{S}$ & $S$ \\
\hline 41 & $\begin{array}{l}\text { Domiate } \\
\text { cheese }\end{array}$ & k.pnemo & $\mathrm{R}$ & $\mathrm{R}$ & $\mathrm{S}$ & $\mathrm{S}$ & $\mathrm{R}$ & $\mathrm{R}$ & $\mathrm{R}$ & $\mathrm{R}$ & $\mathrm{R}$ & $\mathrm{R}$ & $\mathrm{S}$ & $\mathrm{S}$ & $\mathrm{R}$ \\
\hline 75 & $\begin{array}{l}\text { kareish } \\
\text { cheese }\end{array}$ & k.pnemo & $\mathrm{R}$ & $\mathrm{R}$ & $\mathrm{S}$ & $\mathrm{S}$ & $\mathrm{R}$ & $\mathrm{R}$ & $\mathrm{R}$ & $\mathrm{R}$ & $\mathrm{R}$ & $\bar{R}$ & $\mathrm{R}$ & $S$ & $\bar{R}$ \\
\hline 79 & $\begin{array}{l}\text { Ice } \\
\text { cream }\end{array}$ & k.pnemo & $\mathrm{R}$ & $\mathrm{R}$ & $\mathrm{S}$ & $\mathrm{S}$ & $\mathrm{R}$ & $\mathrm{R}$ & $\mathrm{R}$ & $\mathrm{R}$ & $\mathrm{R}$ & $\mathrm{R}$ & $\mathrm{S}$ & $\mathrm{S}$ & $S$ \\
\hline 10 & Milk & k. oxy & $\mathrm{R}$ & $\mathrm{R}$ & $\mathrm{S}$ & $\mathrm{S}$ & $\mathrm{R}$ & $\mathrm{S}$ & $\mathrm{R}$ & $\mathrm{R}$ & $\mathrm{R}$ & $\mathrm{R}$ & $\mathrm{S}$ & $\mathrm{S}$ & $\mathrm{R}$ \\
\hline 13 & Milk & k. oxy & $\mathrm{R}$ & $\mathrm{R}$ & $\mathrm{S}$ & $\mathrm{S}$ & $\mathrm{R}$ & $\mathrm{S}$ & $\mathrm{R}$ & $\mathrm{R}$ & $\mathrm{R}$ & $\mathrm{R}$ & $\mathrm{S}$ & $\mathrm{R}$ & $\mathrm{R}$ \\
\hline 23 & $\begin{array}{l}\text { Domiate } \\
\text { cheese }\end{array}$ & K.oxy & $\mathrm{R}$ & $\mathrm{R}$ & $\mathrm{S}$ & $\mathrm{S}$ & $\mathrm{R}$ & $\mathrm{S}$ & $\mathrm{R}$ & $\mathrm{R}$ & $\mathrm{R}$ & $S$ & $S$ & $\mathrm{R}$ & $\mathrm{R}$ \\
\hline 51 & $\begin{array}{l}\text { kareish } \\
\text { cheese }\end{array}$ & k. oxy & $\mathrm{R}$ & $\mathrm{R}$ & $\mathrm{S}$ & $S$ & $\mathrm{R}$ & $\mathrm{R}$ & $\mathrm{R}$ & $\mathrm{R}$ & $\mathrm{R}$ & $\mathrm{R}$ & $\mathrm{S}$ & $\mathrm{S}$ & $\mathrm{R}$ \\
\hline 51 & $\begin{array}{l}\text { kareish } \\
\text { cheese }\end{array}$ & k.oxy & $\mathrm{R}$ & $\mathrm{R}$ & $S$ & $S$ & $\mathrm{R}$ & $\mathrm{R}$ & $\mathrm{R}$ & $\mathrm{R}$ & $\mathrm{R}$ & $\mathrm{R}$ & $S$ & $\mathrm{~S}$ & $\mathrm{R}$ \\
\hline 6 & Milk & $\begin{array}{l}\text { Enterobac- } \\
\text { ter }\end{array}$ & $\mathrm{R}$ & $\mathrm{R}$ & $\mathrm{S}$ & $\mathrm{S}$ & $\mathrm{R}$ & $\mathrm{R}$ & $\mathrm{R}$ & $\mathrm{R}$ & $\mathrm{R}$ & $\mathrm{R}$ & $\mathrm{R}$ & $\mathrm{R}$ & $\mathrm{R}$ \\
\hline 12 & Milk & $\begin{array}{l}\text { Enterobac- } \\
\text { ter }\end{array}$ & $\mathrm{S}$ & $\mathrm{S}$ & $S$ & $S$ & $\mathrm{R}$ & $\mathrm{R}$ & $\mathrm{R}$ & $\mathrm{R}$ & $\mathrm{R}$ & $\mathrm{S}$ & $S$ & $\mathrm{~S}$ & $S$ \\
\hline 12 & Milk & $\begin{array}{l}\text { Enterobac- } \\
\text { ter }\end{array}$ & $\mathrm{R}$ & $\mathrm{R}$ & $\mathrm{S}$ & $\mathrm{S}$ & $\mathrm{R}$ & $\mathrm{R}$ & $\mathrm{R}$ & $\mathrm{R}$ & $\mathrm{R}$ & $S$ & $S$ & $\mathrm{~S}$ & $\mathrm{R}$ \\
\hline 14 & Milk & $\begin{array}{l}\text { Enterobac- } \\
\text { ter }\end{array}$ & $\mathrm{R}$ & $\mathrm{R}$ & $\mathrm{S}$ & $\mathrm{S}$ & $\mathrm{R}$ & $\mathrm{R}$ & $\mathrm{R}$ & $\mathrm{R}$ & $\mathrm{R}$ & $\mathrm{S}$ & $\mathrm{S}$ & $\mathrm{R}$ & $\mathrm{R}$ \\
\hline 14 & Milk & $\begin{array}{l}\text { Enterobac- } \\
\text { ter }\end{array}$ & $\mathrm{R}$ & $\mathrm{S}$ & $\mathrm{S}$ & $\mathrm{S}$ & $\mathrm{R}$ & $\mathrm{R}$ & $\mathrm{R}$ & $\mathrm{R}$ & $\mathrm{R}$ & $S$ & $S$ & $\mathrm{~S}$ & $\mathrm{R}$ \\
\hline 14 & Milk & $\begin{array}{l}\text { Enterobac- } \\
\text { ter }\end{array}$ & $\mathrm{R}$ & $\mathrm{S}$ & $\mathrm{S}$ & $\mathrm{S}$ & $\mathrm{R}$ & $\mathrm{R}$ & $\mathrm{R}$ & $\mathrm{R}$ & $\mathrm{R}$ & $S$ & $S$ & $S$ & $\mathrm{R}$ \\
\hline 35 & $\begin{array}{l}\text { Domiate } \\
\text { cheese }\end{array}$ & $\begin{array}{l}\text { Enterobac- } \\
\text { ter }\end{array}$ & $\mathrm{R}$ & $\mathrm{R}$ & $\mathrm{S}$ & $\mathrm{S}$ & S & $S$ & $\mathrm{R}$ & $\mathrm{R}$ & $\mathrm{R}$ & $\mathrm{R}$ & $S$ & $S$ & $\mathrm{R}$ \\
\hline 97 & $\begin{array}{l}\text { Ice } \\
\text { cream }\end{array}$ & $\begin{array}{l}\text { Enterobac- } \\
\text { ter }\end{array}$ & $\mathrm{R}$ & $S$ & $\mathrm{~S}$ & $\mathrm{~S}$ & $\mathrm{R}$ & $\mathrm{R}$ & $\mathrm{R}$ & $\mathrm{R}$ & $\mathrm{R}$ & $S$ & $S$ & $\mathrm{~S}$ & $\mathrm{R}$ \\
\hline 11 & Milk & $\begin{array}{l}\text { Citerobac- } \\
\text { ter }\end{array}$ & $\mathrm{R}$ & $\mathrm{R}$ & $\mathrm{S}$ & $\mathrm{S}$ & $\mathrm{R}$ & $\mathrm{R}$ & $\mathrm{R}$ & $\mathrm{R}$ & $\mathrm{R}$ & $\bar{R}$ & $\mathrm{~S}$ & $S$ & $\mathrm{R}$ \\
\hline 11 & Milk & $\begin{array}{l}\text { Citerobac- } \\
\text { ter }\end{array}$ & $\mathrm{R}$ & $\mathrm{R}$ & $\mathrm{S}$ & $\bar{S}$ & $\mathrm{R}$ & $\mathrm{R}$ & $\mathrm{R}$ & $\mathrm{R}$ & $\mathrm{R}$ & $S$ & $S$ & $\mathrm{R}$ & $\mathrm{R}$ \\
\hline 11 & Milk & $\begin{array}{l}\text { Citerobac- } \\
\text { ter }\end{array}$ & $\mathrm{R}$ & $S$ & $\mathrm{~S}$ & $\mathrm{~S}$ & $\mathrm{R}$ & $\mathrm{R}$ & $\mathrm{R}$ & $\mathrm{R}$ & $\mathrm{R}$ & $S$ & $S$ & $S$ & $\mathrm{R}$ \\
\hline 12 & Milk & $\begin{array}{l}\text { Citerobac- } \\
\text { ter }\end{array}$ & $\mathrm{R}$ & $\mathrm{R}$ & S & $\mathrm{S}$ & $\mathrm{R}$ & $\mathrm{R}$ & $\mathrm{R}$ & $\mathrm{R}$ & $\mathrm{R}$ & $\mathrm{S}$ & $\mathrm{R}$ & $\mathrm{R}$ & $\mathrm{R}$ \\
\hline 49 & $\begin{array}{l}\text { Domiate } \\
\text { cheese }\end{array}$ & $\begin{array}{l}\text { Citerobac- } \\
\text { ter }\end{array}$ & $\mathrm{R}$ & $\mathrm{R}$ & $\mathrm{S}$ & $\mathrm{S}$ & $\mathrm{R}$ & $\mathrm{R}$ & $\mathrm{R}$ & $\mathrm{R}$ & $\mathrm{R}$ & $S$ & $S$ & $\mathrm{R}$ & $\mathrm{R}$ \\
\hline 58 & $\begin{array}{l}\text { kareish } \\
\text { cheese }\end{array}$ & $\begin{array}{l}\text { Citerobac- } \\
\text { ter }\end{array}$ & $\mathrm{R}$ & $\mathrm{R}$ & $\mathrm{S}$ & $S$ & $\mathrm{R}$ & $\mathrm{R}$ & $\mathrm{R}$ & $\mathrm{R}$ & $\mathrm{R}$ & $\bar{R}$ & $S$ & $S$ & $\mathrm{R}$ \\
\hline 58 & $\begin{array}{l}\text { kareish } \\
\text { cheese }\end{array}$ & $\begin{array}{l}\text { Citerobac- } \\
\text { ter }\end{array}$ & $\mathrm{R}$ & $\mathrm{R}$ & $\mathrm{S}$ & $\mathrm{S}$ & $\mathrm{R}$ & $\mathrm{R}$ & $\mathrm{R}$ & $\mathrm{R}$ & $\mathrm{R}$ & $S$ & $\mathrm{R}$ & $\mathrm{S}$ & $\mathrm{R}$ \\
\hline 59 & $\begin{array}{l}\text { kareish } \\
\text { cheese }\end{array}$ & $\begin{array}{l}\text { Citerobac- } \\
\text { ter }\end{array}$ & $\mathrm{R}$ & $S$ & $\mathrm{~S}$ & $\mathrm{~S}$ & $\mathrm{R}$ & $\mathrm{S}$ & $\mathrm{R}$ & $\mathrm{R}$ & $\mathrm{R}$ & $S$ & $S$ & $\mathrm{~S}$ & $S$ \\
\hline 12 & Milk & Serratia & $\mathrm{R}$ & $\mathrm{S}$ & $\mathrm{S}$ & $\mathrm{S}$ & $\mathrm{R}$ & $\mathrm{R}$ & $\mathrm{R}$ & $\mathrm{R}$ & $\mathrm{R}$ & $\mathrm{S}$ & $\mathrm{S}$ & $\mathrm{R}$ & $\mathrm{R}$ \\
\hline
\end{tabular}

$\mathrm{P}=$ Pencillin, $\mathrm{AM}=$ Ampicillin, $\mathrm{IPM}=$ Impipenem, $\mathrm{MEM}=$ Meropenem, $\mathrm{CL}=$ Cefalaxim $, \mathrm{CEC}=\mathrm{Cefaclor}, \mathrm{FOX}=$ Cefoxitin, $\mathrm{CAZ}=$ Ceftazidime, $\mathrm{CTX}=$ Cefotaxime,, $\mathrm{FEP}=$ Cefepime, $\mathrm{ATM}=$ Azteronam, $\mathrm{AMC}=$ Amoxycil-

lin/clavulinic, TPZ = Pipercillin/Tazobactam, 
Table 5: Antimicrobial resistance profiles in the identified Enterobacteriaceae spp.

\begin{tabular}{|c|c|c|c|c|c|c|c|c|c|c|c|c|c|c|c|c|c|c|c|}
\hline \multicolumn{2}{|c|}{$\begin{array}{l}\text { Used anti- } \\
\text { biotic }\end{array}$} & \multicolumn{6}{|c|}{ Raw milk } & \multicolumn{5}{|c|}{ Damietta Cheese } & \multicolumn{4}{|c|}{ Kareish Cheese } & \multicolumn{3}{|c|}{ Ice cream } \\
\hline & \multirow{12}{*}{ 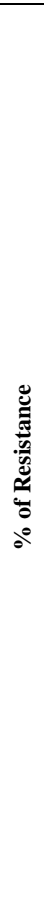 } & E.coli & K. P & k.O & $E$ & $C$ & $S$ & E.coli & K. $P$ & k.O & $E$ & $C$ & E.coli & K.P & k.O & $C$ & E.coli & K.P & $E$ \\
\hline $\mathbf{p}$ & & $\begin{array}{c}88.88 \\
(8 / 9)\end{array}$ & $\begin{array}{l}100 \\
(2 / 2)\end{array}$ & $\begin{array}{l}100 \\
(2 / 2)\end{array}$ & $\begin{array}{c}83.33 \\
(5 / 6)\end{array}$ & $\begin{array}{c}100 \\
(4 / 4)\end{array}$ & $\begin{array}{c}100 \\
(1 / 1)\end{array}$ & $\begin{array}{c}100 \\
(5 / 5)\end{array}$ & $\begin{array}{l}100 \\
(3 / 3\end{array}$ & $\begin{array}{c}100 \\
(1 / 1)\end{array}$ & $\begin{array}{c}100 \\
(1 / 1)\end{array}$ & $\begin{array}{c}100 \\
(1 / 1)\end{array}$ & $\begin{array}{c}90 \\
(9 / 10)\end{array}$ & $\begin{array}{c}100 \\
(2 / 2)\end{array}$ & $\begin{array}{l}100 \\
(2 / 2)\end{array}$ & $\begin{array}{l}100 \\
(3 / 3)\end{array}$ & $\begin{array}{c}100 \\
(5 / 5)\end{array}$ & $\begin{array}{c}100 \\
(1 / 1)\end{array}$ & $\begin{array}{l}100 \\
(1 / 1)\end{array}$ \\
\hline $\mathbf{A M}$ & & $\begin{array}{c}66.66 \\
(6 / 9)\end{array}$ & $\begin{array}{l}100 \\
(2 / 2)\end{array}$ & $\begin{array}{l}100 \\
(2 / 2)\end{array}$ & $\begin{array}{c}50 \\
(2 / 4)\end{array}$ & $\begin{array}{c}75 \\
(3 / 4)\end{array}$ & $\begin{array}{c}0 \\
(0 / 1)\end{array}$ & $\begin{array}{c}60 \\
(3 / 5)\end{array}$ & $\begin{array}{l}100 \\
(3 / 3\end{array}$ & $\begin{array}{c}100 \\
(1 / 1)\end{array}$ & $\begin{array}{c}100 \\
(1 / 1)\end{array}$ & $\begin{array}{c}100 \\
(1 / 1)\end{array}$ & $\begin{array}{c}50 \\
(5 / 10)\end{array}$ & $\begin{array}{c}100 \\
(2 / 2)\end{array}$ & $\begin{array}{l}100 \\
(2 / 2)\end{array}$ & $\begin{array}{c}66.66 \\
(2 / 3)\end{array}$ & $\begin{array}{c}80 \\
(4 / 5)\end{array}$ & $\begin{array}{l}100 \\
(1 / 1\end{array}$ & $\begin{array}{c}0 \\
(0 / 1)\end{array}$ \\
\hline CL & & $\begin{array}{c}100 \\
(9 / 9)\end{array}$ & $\begin{array}{c}100 \\
(2 / 2)\end{array}$ & $\begin{array}{c}100 \\
(2 / 2)\end{array}$ & $\begin{array}{c}100 \\
(6 / 6)\end{array}$ & $\begin{array}{l}100 \\
(4 / 4)\end{array}$ & $\begin{array}{c}100 \\
(1 / 1)\end{array}$ & $\begin{array}{c}100 \\
(5 / 5)\end{array}$ & $\begin{array}{l}100 \\
(3 / 3\end{array}$ & $\begin{array}{c}100 \\
(1 / 1)\end{array}$ & $\begin{array}{c}0 \\
(0 / 1)\end{array}$ & $\begin{array}{c}100 \\
(1 / 1)\end{array}$ & $\begin{array}{c}90 \\
(9 / 10)\end{array}$ & $\begin{array}{c}100 \\
(2 / 2)\end{array}$ & $\begin{array}{c}100 \\
(2 / 2)\end{array}$ & $\begin{array}{l}100 \\
(3 / 3)\end{array}$ & $\begin{array}{c}100 \\
(5 / 5)\end{array}$ & $\begin{array}{c}100 \\
(1 / 1)\end{array}$ & $\begin{array}{r}100 \\
(1 / 1)\end{array}$ \\
\hline CEC & & $\begin{array}{c}100 \\
(9 / 9)\end{array}$ & $\begin{array}{l}100 \\
(2 / 2)\end{array}$ & $\begin{array}{c}0 \\
(0 / 2)\end{array}$ & $\begin{array}{c}100 \\
(6 / 6)\end{array}$ & $\begin{array}{c}100 \\
(4 / 4)\end{array}$ & $\begin{array}{c}100 \\
(1 / 1)\end{array}$ & $\begin{array}{c}100 \\
(5 / 5)\end{array}$ & $\begin{array}{l}100 \\
(3 / 3\end{array}$ & $\begin{array}{c}0 \\
(0 / 1)\end{array}$ & $\begin{array}{c}0 \\
(0 / 1)\end{array}$ & $\begin{array}{c}100 \\
(1 / 1)\end{array}$ & $\begin{array}{c}100 \\
(10 / 10)\end{array}$ & $\begin{array}{c}100 \\
(2 / 2)\end{array}$ & $\begin{array}{l}100 \\
(2 / 2)\end{array}$ & $\begin{array}{l}100 \\
(3 / 3)\end{array}$ & $\begin{array}{c}100 \\
(5 / 5)\end{array}$ & $\begin{array}{c}100 \\
(1 / 1)\end{array}$ & $\begin{array}{l}100 \\
(1 / 1)\end{array}$ \\
\hline FOX & & $\begin{array}{l}100 \\
(9 / 9)\end{array}$ & $\begin{array}{c}100 \\
(2 / 2)\end{array}$ & $\begin{array}{c}100 \\
(2 / 2)\end{array}$ & $\begin{array}{c}100 \\
(6 / 6)\end{array}$ & $\begin{array}{c}100 \\
(4 / 4)\end{array}$ & $\begin{array}{c}100 \\
(1 / 1)\end{array}$ & $\begin{array}{c}100 \\
(5 / 5)\end{array}$ & $\begin{array}{l}100 \\
(3 / 3\end{array}$ & $\begin{array}{c}100 \\
(1 / 1)\end{array}$ & $\begin{array}{c}100 \\
(1 / 1)\end{array}$ & $\begin{array}{c}100 \\
(1 / 1)\end{array}$ & $\begin{array}{c}100 \\
(10 / 10)\end{array}$ & $\begin{array}{c}100 \\
(2 / 2)\end{array}$ & $\begin{array}{c}100 \\
(2 / 2)\end{array}$ & $\begin{array}{c}100 \\
(3 / 3)\end{array}$ & $\begin{array}{c}100 \\
(5 / 5)\end{array}$ & $\begin{array}{c}100 \\
(1 / 1)\end{array}$ & $\begin{array}{r}100 \\
(1 / 1)\end{array}$ \\
\hline CAZ & & $\begin{array}{l}77.77 \\
(7 / 9)\end{array}$ & $\begin{array}{c}100 \\
(2 / 2)\end{array}$ & $\begin{array}{c}100 \\
(2 / 2)\end{array}$ & $\begin{array}{c}100 \\
(6 / 6)\end{array}$ & $\begin{array}{c}100 \\
(4 / 4)\end{array}$ & $\begin{array}{c}100 \\
(1 / 1)\end{array}$ & $\begin{array}{c}100 \\
(5 / 5)\end{array}$ & $\begin{array}{l}100 \\
(3 / 3\end{array}$ & $\begin{array}{c}100 \\
(1 / 1)\end{array}$ & $\begin{array}{c}100 \\
(1 / 1)\end{array}$ & $\begin{array}{c}100 \\
(1 / 1)\end{array}$ & $\begin{array}{c}100 \\
(10 / 10)\end{array}$ & $\begin{array}{c}100 \\
(2 / 2)\end{array}$ & $\begin{array}{c}100 \\
(2 / 2)\end{array}$ & $\begin{array}{c}100 \\
(3 / 3)\end{array}$ & $\begin{array}{c}100 \\
(5 / 5)\end{array}$ & $\begin{array}{c}100 \\
(1 / 1)\end{array}$ & $\begin{array}{c}100 \\
(1 / 1)\end{array}$ \\
\hline CTX & & $\begin{array}{l}100 \\
(9 / 9)\end{array}$ & $\begin{array}{c}100 \\
(2 / 2)\end{array}$ & $\begin{array}{l}100 \\
(2 / 2)\end{array}$ & $\begin{array}{c}100 \\
(6 / 6)\end{array}$ & $\begin{array}{l}100 \\
(4 / 4)\end{array}$ & $\begin{array}{c}100 \\
(1 / 1)\end{array}$ & $\begin{array}{c}100 \\
(5 / 5)\end{array}$ & $\begin{array}{l}100 \\
(3 / 3\end{array}$ & $\begin{array}{c}100 \\
(1 / 1)\end{array}$ & $\begin{array}{c}100 \\
(1 / 1)\end{array}$ & $\begin{array}{c}100 \\
(1 / 1)\end{array}$ & $\begin{array}{c}100 \\
(10 / 10)\end{array}$ & $\begin{array}{c}100 \\
(2 / 2)\end{array}$ & $\begin{array}{c}100 \\
(2 / 2)\end{array}$ & $\begin{array}{c}100 \\
(3 / 3)\end{array}$ & $\begin{array}{c}100 \\
(5 / 5)\end{array}$ & $\begin{array}{c}100 \\
(1 / 1)\end{array}$ & $\begin{array}{c}100 \\
(1 / 1)\end{array}$ \\
\hline FEP & & $\begin{array}{c}33.33 \\
(3 / 9)\end{array}$ & $\begin{array}{c}100 \\
(2 / 2)\end{array}$ & $\begin{array}{c}100 \\
(2 / 2)\end{array}$ & $\begin{array}{l}16.66 \\
(1 / 6)\end{array}$ & $\begin{array}{c}25 \\
(1 / 4)\end{array}$ & $\begin{array}{c}0 \\
(0 / 1)\end{array}$ & $\begin{array}{c}80 \\
(4 / 5)\end{array}$ & $\begin{array}{c}66.66 \\
(2 / 3\end{array}$ & $\begin{array}{c}0 \\
(0 / 1)\end{array}$ & $\begin{array}{c}100 \\
(1 / 1)\end{array}$ & $\begin{array}{c}0 \\
(0 / 1)\end{array}$ & $\begin{array}{c}40 \\
(4 / 10)\end{array}$ & $\begin{array}{c}100 \\
(2 / 2)\end{array}$ & $\begin{array}{c}100 \\
(2 / 2)\end{array}$ & $\begin{array}{c}33.33 \\
(1 / 3)\end{array}$ & $\begin{array}{c}100 \\
(5 / 5)\end{array}$ & $\begin{array}{c}100 \\
(1 / 1)\end{array}$ & $\begin{array}{c}0 \\
(0 / 1)\end{array}$ \\
\hline ATM & & $\begin{array}{c}11.11 \\
(1 / 9)\end{array}$ & $\begin{array}{c}50 \\
(1 / 2)\end{array}$ & $\begin{array}{c}0 \\
(0 / 2)\end{array}$ & $\begin{array}{c}16.66 \\
(1 / 6)\end{array}$ & $\begin{array}{c}25 \\
(1 / 4)\end{array}$ & $\begin{array}{c}0 \\
(0 / 1)\end{array}$ & $\begin{array}{c}40 \\
(2 / 5)\end{array}$ & $\begin{array}{c}0 \\
(0 / 3\end{array}$ & $\begin{array}{c}0 \\
(0 / 1)\end{array}$ & $\begin{array}{c}0 \\
(0 / 1)\end{array}$ & $\begin{array}{c}0 \\
(0 / 1)\end{array}$ & $\begin{array}{c}30 \\
(3 / 10)\end{array}$ & $\begin{array}{c}50 \\
(1 / 2)\end{array}$ & $\begin{array}{c}0 \\
(0 / 2)\end{array}$ & $\begin{array}{c}33.33 \\
(1 / 3)\end{array}$ & $\begin{array}{c}20 \\
(1 / 5)\end{array}$ & $\begin{array}{c}0 \\
(0 / 1)\end{array}$ & $\begin{array}{c}0 \\
(0 / 1)\end{array}$ \\
\hline AMC & & $\begin{array}{c}33.33 \\
(3 / 9)\end{array}$ & $\begin{array}{c}0 \\
(0 / 2)\end{array}$ & $\begin{array}{c}50 \\
(1 / 2)\end{array}$ & $\begin{array}{l}33.33 \\
(2 / 6)\end{array}$ & $\begin{array}{c}50 \\
(2 / 4)\end{array}$ & $\begin{array}{c}100 \\
(1 / 1)\end{array}$ & $\begin{array}{c}60 \\
(3 / 5)\end{array}$ & $\begin{array}{c}0 \\
(0 / 3\end{array}$ & $\begin{array}{c}100 \\
(1 / 1)\end{array}$ & $\begin{array}{c}0 \\
(0 / 1)\end{array}$ & $\begin{array}{c}0 \\
(0 / 1)\end{array}$ & $\begin{array}{c}40 \\
(4 / 10)\end{array}$ & $\begin{array}{c}100 \\
(2 / 2)\end{array}$ & $\begin{array}{c}0 \\
(0 / 2)\end{array}$ & $\begin{array}{c}0 \\
(0 / 3)\end{array}$ & $\begin{array}{c}20 \\
(1 / 5)\end{array}$ & $\begin{array}{c}0 \\
(0 / 1)\end{array}$ & $\begin{array}{c}0 \\
(0 / 1)\end{array}$ \\
\hline TPZ & & $\begin{array}{c}66.66 \\
(6 / 9)\end{array}$ & $\begin{array}{c}50 \\
(2 / 2)\end{array}$ & $\begin{array}{c}100 \\
(2 / 2)\end{array}$ & $\begin{array}{c}83.33 \\
(5 / 6)\end{array}$ & $\begin{array}{c}100 \\
(4 / 4)\end{array}$ & $\begin{array}{c}100 \\
(1 / 1)\end{array}$ & $\begin{array}{l}100 \\
(5 / 5\end{array}$ & $\begin{array}{c}66.66 \\
(2 / 3\end{array}$ & $\begin{array}{c}100 \\
(1 / 1)\end{array}$ & $\begin{array}{c}100 \\
(1 / 1)\end{array}$ & $\begin{array}{c}100 \\
(1 / 1)\end{array}$ & $\begin{array}{c}80 \\
(8 / 10)\end{array}$ & $\begin{array}{c}100 \\
(2 / 2)\end{array}$ & $\begin{array}{c}100 \\
(2 / 2)\end{array}$ & $\begin{array}{c}66.66 \\
(2 / 3)\end{array}$ & $\begin{array}{c}80 \\
(4 / 5)\end{array}$ & $\begin{array}{c}0 \\
(0 / 1)\end{array}$ & $\begin{array}{c}100 \\
(1 / 1)\end{array}$ \\
\hline
\end{tabular}

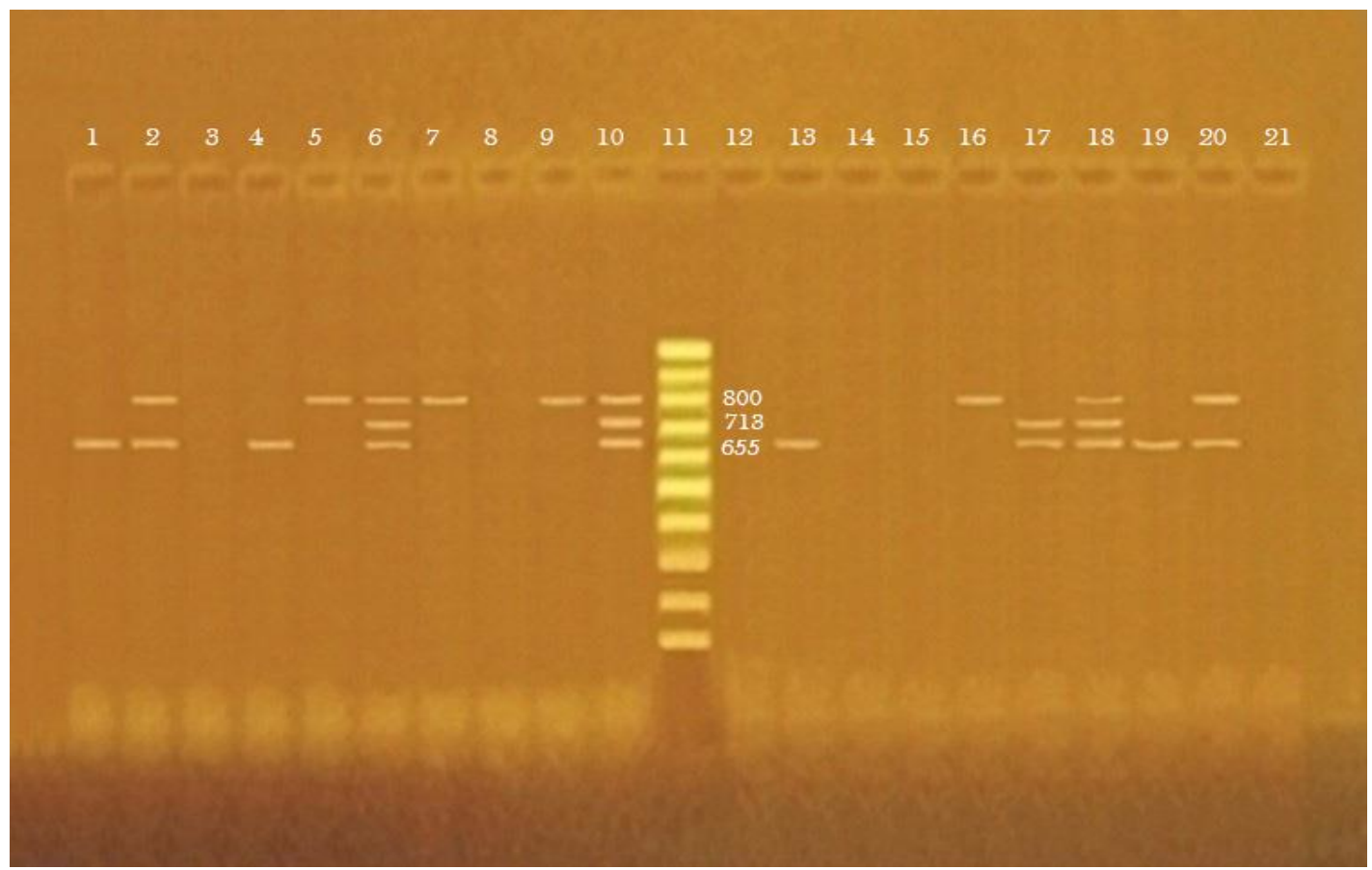

Figure 1: Agarose gel electrophoresis of multiplex PCR amplification of blaCTX-M1, blaSHV and blaTEM in E. coli with expected amplicon size $\sim 655,713,800$ bp respectively. Lane 11 is DNA ladder; lane 10 is positive control while lane12 is negative control 


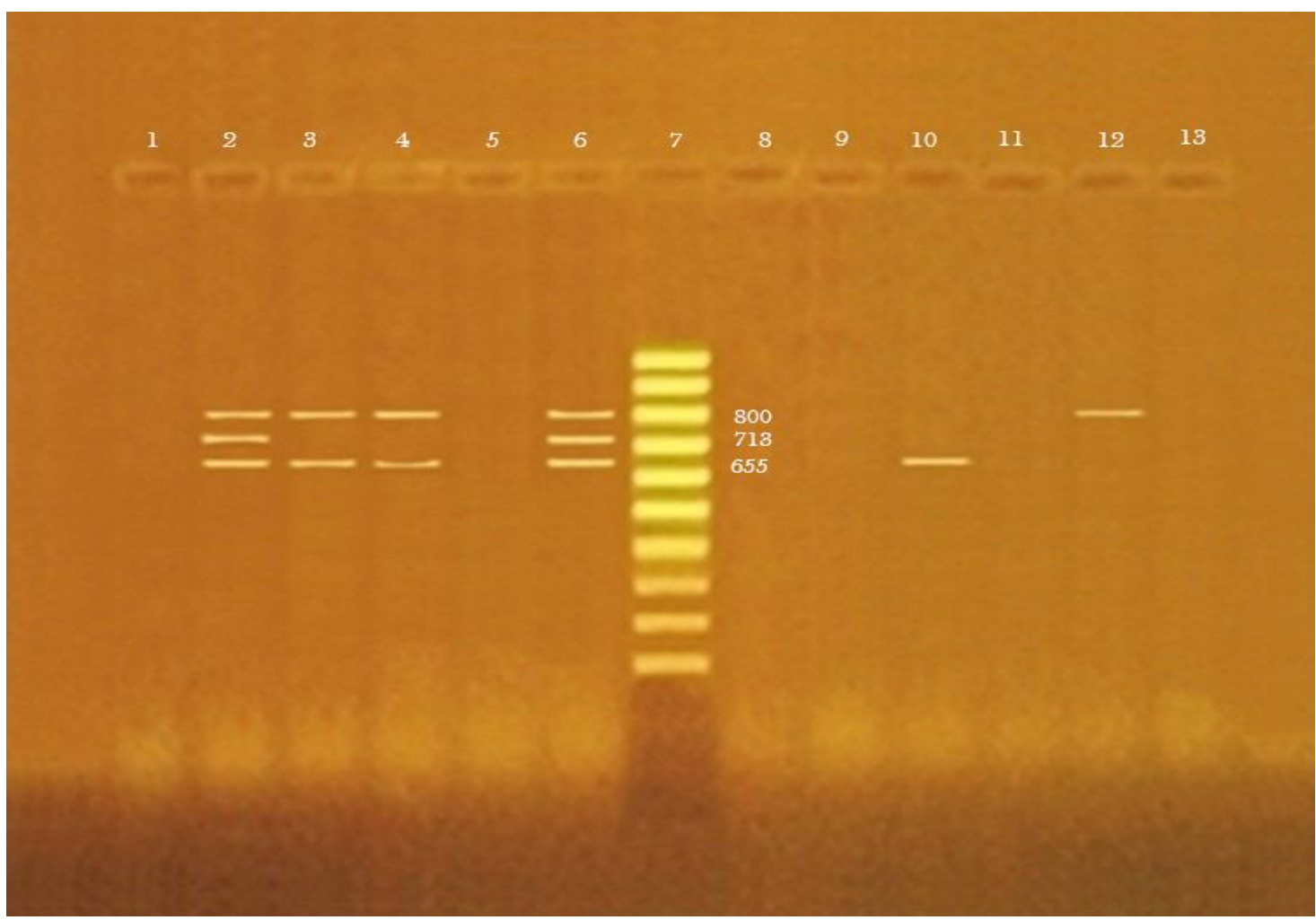

Figure 2: Agarose gel electrophoresis of multiplex PCR amplification of blaCTX-M1, blaSHV and blaTEM in Klebseilla spp. with expected amplicon size $\sim 655,713,800$ bp respectively. Lane 7 is DNA ladder; lane 6 is positive control while lane 8 is negative control

\section{Discussion}

In Egypt, there is a lack of data regarding ESBLs producing Enterobacteriaceae from milk and dairy product with a limited report about the surveillance of ESBLs producing $E$. coli in dairy cattle (3). Therefore, the present study was set to characterize ESBLs producing Enterobacteriaceae in some dairy products sold in Damietta city. In this study, the overall detection rate of ESBL producer $E$. coli in the examined dairy samples was $17 \%$. A nearly similar detection rate was previously reported from bulk tank milk samples from German dairy farms (1); while a low frequency of ESBLs $(0.7 \%)$ was reported in raw milk from the Czech Republic (14). In contrast, a higher detection rate $42.8 \%$ (114/266) of ESBL-producing E.coli was previously reported in Egypt from dairy cattle (3). It is really difficult to compare studies from Egypt and other countries due to lack of reports and different methods being used for determining the presence of ESBL producing Enterobacteriaceae. In one study, the authors failed to determine ESBL-producing isolates in bulk tank milk from 100 different Swiss dairy farms (15). In another study from Turkey, the authors identified ESBL-producing Enterobacteriaceae in 100 raw milk with the percentage of $43.6 \%$ (16). In a recent study from Sudan, the authors detected ESBL production in 17 out of the 22 isolated E. coli $(29.3 \%)$ from 70 raw cow milk samples collected from different villages in Aljazira state (17). A prevalence of $42.22 \%$ ESBL-positive $E$. coli isolates out of $45 \mathrm{E}$. coli strains was identified from 24 typical Slovak cheeses made from raw milk (18).

In the present study, $13.5 \%$ of the identified isolates and $6 \%$ of the examined samples were classified as ESBL producing Klebsiella pneumonia. Different detection rate was reported from recent studies in India (19) and Sudan (17). In those studies, detection rate of $1.5 \%$ and $44.8 \%$ of $K$. pneumonia were identified as ESBL producing Klebsiella pneumonia from raw milk. ESBLs producing Enterobacteriaceae has been described for the first time from 
hospitalized humans but recently, several researchers from different countries reported its dissemination in the community and also in healthy food producing animals worldwide (1, $3.5,15)$.

Resistance to antimicrobial agents represents a real challenge in Egypt, with high burden on the Egyptian health care system (20). In that study, the authors found that 151 out of 355 $(42.5 \%)$ of the Klebsiella spp. and 47 of 87 (54\%) of Escherichia coli from the patient in intensive care units were identified as ESBL producers. Several studies have discussed the resistance spectra of different ESBL producers regardless their origin (i.e. human, animal or food origins) (5,15-16). Globally, ESBL-producing microorganisms are one of the most severe problematic multi-resistant and are being identified with increased frequency (4). Our results showed that resistance to two or more antibiotics was frequently encountered among the recovered isolates. As the production of most ESBLs is plasmids encoding, co-resistance to other groups of antibiotics is a common sequel (15). Remarkably, the range of resistance in our study was sufficiently worrisome. For instance, if an infection caused by any identified strains (as that observed in this study) it could represent a great concern due to limited therapeutic options. According to latest report of Infectious Diseases Society of America, ESBL-producing E coli and Klebsiella spp. were recognized as one of the six drug-resistant microbes that urgently required new remedies (21). Our genotypic characterization of the positive dairy samples by PCR assays revealed that $48 \%$ of the positive dairy samples were possessed blaCTXM1encoding CTX-M broad-spectrum $\beta$-lactamases, while other genes like blaTEM and blaSHV were detected in $44 \%$ and $14.8 \%$, respectively. This finding was in agreement with that previously reported $(22,24,15,23,16)$. Unlike to our finding, several authors reported the absence of the blaCTX-M gene but identified only blaTEM and blaSHV genes in 15 and 4 isolates (18). The blaSHV-110, blaSHV-111, and blaCMY-41 genes have been identified from Domiati cheese from small producers in El Behera and Alexandria governments, Egypt
(5). The production of broad-spectrum lactamases could provoke a significant clinical consequences with a resultant threaten the successful treatment of infectious diseases resulting in exacerbate public-health concerns (18).

\section{Conclusion}

In conclusion, there is clear evidence of circulation of antibiotic-resistant food borne ESBL producing Enterobacteriaceae in the examined dairy samples. As the majority of Egyptian population still consume raw milk and its product like soft cheese e.g. Domiati and Kareish cheese which contained ESBL producing Enterobacteriaceae, the concern about increasing the risk of a spread of such multi-drug resistant pathogens raises with a potential asymptomatic colonization and complication of systemic infection in human subjects and this could be achieved with safe use of antibiotics, reinforced sanitary measures, and a continues investigation of the phenomenon of antibiotic resistance in food producing animals.

\section{Conflict of interest}

The authors declare that they have no conflict of interest.

\section{References}

1. Odenthal S, Akineden Ö \&Usleber E. Extended-spectrum $\beta$-lactamase producing Enterobacteriaceae in bulk tank milk from German dairy farms. International journal of food microbiology 2016; 238: 72-8.

2. Horigan V , Kosmider R D , Horton R A , Randall L \& Simons R. R. L. . An assessment of evidence data gaps in the investigation of possible transmission routes of extended spectrum $\beta$-lactamase producing Escherichia coli from livestock to humans in the UK. Preventive veterinary medicine 2016; 124: 1-8.

3. Braun SD, Ahmed MFE, El-Adawy H, Hotzel H, Engelmann I, Weiß D, Monecke S \&Ehricht R . Surveillance of Extended-Spectrum Beta-Lactamase-Producing Escherichia coli in Dairy Cattle Farms in the Nile Delta, Egypt. Front. Microbiol. 7:1020. doi: 10.3389/ fmicb. 2016; 01020.

4. OIE .Terrestrial Animal Health Code. Risk Analysis for Antimicrobial Resistance Arising from the Use of Antimicrobials in Animals. Version7 2014. 
5. Hammad A M , Ishida Y \& Shimamoto T. Prevalence and molecular characterization of ampicillin-resistant Enterobacteriaceae isolated from traditional Egyptian Domiati cheese. Journal of food protection 2009; 72 (3): 624-30.

6. Seiffert S N, Hilty M, Perreten V \& Endimiani A. Extended-spectrum cephalosporin-resistant Gram-negative organisms in livestock: an emerging problem for human health? Drug Resistance Updates 2013; 16 (1-2): 22-45.

7. Dahmen S, Métayer V, Gay E, Madec J Y \& Haenni M. Characterization of extended-spectrum beta-lactamase (ESBL)-carrying plasmids and clones of Enterobacteriaceae causing cattle mastitis in France. Veterinary microbiology 2013; 162 (2-4): 793-99.

8. Zeinhom M M \& Abdel-Latef G. K. Public health risk of some milk borne pathogens. BeniSuef University Journal of Basic and Applied Sciences 2014; 3(3): 209-15.

9. Roberts D\& Green wood M. Practical Food Microbiology, $3^{\text {rd }}$. Section 10: confirmatory biochemical testes. Blackwell 2003.

10. Kok T ,Worswich D \& Gowans E. Some serological techniques for microbial and viral infections. In Practical Medical Microbiology (Collee J , Fraser A, Marmion B and Simmons A, eds.) $14^{\text {th }}$ ed., Edinburgh, Churchill Livingstone, UK 1996.

11. CLSI. Performance Standards for Antimicrobial Susceptibility Testing. 27th ed. CLSI supplements M100. Wayne, PA: Clinical and Laborat ory Standards Institute 2017.

12. Ogutu J, Zhang Q, Huang Y, Yan H, Su L, Gao B, Zhang W, Zhao J, Cai W, Li W, Hong Zhao H, Chen Y, Song W, Chen X, Fu Y \& Zhang F. Development of a multiplex PCR system and its application in detection of blaSHV, blaTEM, blaCTXM-1, blaCTX-M-9 and blaOXA-1 group genes in clinical Klebsiella pneumoniae and E. coli strains. The J. of Antibiotics 2015 ; 68: 725-33.

13. Perez F, Jones H, Hanson N \& Geyer C. Global challenge of multidrug-resistant Acinetobacter baumannii. Antimicrob. Agents Chemother. 2007; 51: 3471-84.

14. Skočková A, Bogdanovičoá K, Koláčková I \& Karpíšková R . Antimicrobial-Resistant and Extended-Spectrum $\beta$-Lactamase-Producing Escherichia coli in Raw Cow's Milk. Journal of food protection 2015; 78(1): 72-7.

15. Geser N, Stephan R \& Hächler H. Occurrence and characteristics of extended-spectrum $\beta$ lactamase (ESBL) producing Enterobacteriaceae in food producing animals, minced meat and raw milk.
BMC veterinary research 2012; 8(1): 21.

16. Tekiner İ H \& Özpınar H. Occurrence and characteristics of extended spectrum beta-lactamases-producing Enterobacteriaceae from foods of animal origin. brazilian journal of microbiology 2016 ; 47(2): 444-51.

17. Badri A M , Ibrahim I T , Mohamed S G, Garbi M I , Kabbashi, A S \& Arbab M. H. Prevalence of extended spectrum beta lactamase (ESBL) producing Escherichia coli, and Klebsiella pneumoniae isolated from raw milk samples in $\mathrm{Al}$ Jazirah state, Sudan. Mol. Biol, 2017: 7(1000201), 10-4172.

18. Vrabec M, Lovayová V, Dudriková K , Gallo J \& Dudriková, E .Antibiotic resistance and prevalence of Enterococcus spp. and Escherichia coli isolated from bryndza cheese. Italian Journal of Animal Science 2015; 14(4): 3968.

19. Koovapra S , Bandyopadhyay S , Das G , Bhattacharyya D , Banerjee J , Mahanti A \& Dimri, U. Molecular signature of extended spectrum $\beta$-lactamase producing Klebsiella pneumoniae isolated from bovine milk in eastern and north-eastern India. Infection, Genetics and Evolution 2016; 44: 395402.

20. Talaat M , El-Shokry M , El-Kholy J , Ismail G, Kotb S , Hafez S \& Lessa F. C. National surveillance of health care-associated infections in Egypt: developing a sustainable program in a resource-limited country. American journal of infection control 2016 ; 44(11): 1296-301.

21. Pitout J D\& Laupland KB . Extended-spectrum $\beta$-lactamase-producing Enterobacteriaceae: an emerging public-health concern. The Lancet infectious diseases 2008; 8(3): 159-66.

22. Amador P , Fernandes R , Prudêncio C \& Brito L. Resistance to $\beta$-lactams in bacteria isolated from different types of Portuguese cheese. International Journal of Molecular Sciences 2009; 10 (4): 1538-155.

23. Warjri I, Dutta T K , Lalzampuia H \& Chandra, R. Detection and characterization of extendedspectrum $\beta$-lactamases (blaCTX-M-1 and blaSHV) producing Escherichia coli, Salmonella spp. and Klebsiella pneumoniae isolated from humans in Mizoram. Veterinary world 2015; 8(5): 599.

24. El-Domany R, Emara M, El-Magd M, Moustafa W, Abdeltwab N. Emergence of imipenem-resistant Pseudomonas aeruginosa clinical isolates from Egypt coharboring vim and imp carbapenemases. Microbial Drug Resistance 2017; 23:682-6. 